\title{
Viral Hepatitis with Acute Hemoglobinuria
}

\author{
Jagabandhu Ghosh ${ }^{1}$ Joydeep Ghosh ${ }^{2}$ \\ ${ }^{1}$ Department of Paediatrics, I.P.G.M.E.R and S.S.K.M Hospital, Kolkata, \\ West Bengal, India \\ 2 Department of Biotechnology, Heritage Institute of Technology, \\ Kolkata, West Bengal, India
}

\begin{abstract}
Address for correspondence Jagabandhu Ghosh, MD (PAED), Ushashi Housing Society, 245 Vivekananda Road, Kolkata 700006, India (e-mail: jbghosh@yahoo.com).
\end{abstract}

J Pediatr Infect Dis 2015;10:22-24.

\begin{abstract}
Keywords

- hepatitis

- G6PD

- viral

- hemolysis

- intravascular

A 7-year-old male child presented with moderate degree fever, yellowish discoloration of eyes and urine. Examination on admission revealed severe anemia, jaundice, hepatomegaly, and splenomegaly. On the day following admission, the child showed evidence of blackish discoloration of urine. The diagnosis was established as viral A hepatitis with glucose-6-phosphate dehydrogenase (G6PD) deficiency. The child recovered with supportive therapy. We suggest that either universal immunization against hepatitis A, or routine newborn screening for G6PD deficiency, could prevent the serious morbidity or mortality that can occur when these two conditions coexist.
\end{abstract}

\section{Introduction}

Acute viral hepatitis A is widely prevalent in India. ${ }^{1}$ Viral hepatitis is the leading of acute hepatitis in children in our country, and hepatitis A is the most common type of viral hepatitis. Hepatitis A does not commonly present with severe anemia unless it is complicated by fulminant hepatic failure (FHF) and significant blood loss. However, in patients with glucose-6-phosphate dehydrogenase (G6PD) deficiency, the most common inherited enzyme deficiency worldwide, ${ }^{2}$ hepatitis A may cause severe anemia in absence of major blood loss. This chance association has been reported earlier by Sarkar et al. ${ }^{3}$ The coincidence of acute hepatitis A and G6PD deficiency may cause acute intravascular hemolysis, manifest as pallor, icterus, hepatosplenomegaly, and dark-colored urine. The pathogenetic mechanism of hemolytic anemia in hepatitis A infection is ill-understood, but it has been reported to be autoimmune mediated in at least some cases. ${ }^{4,5}$ Here, we report a case of acute hepatitis A complicated by FHF and acute intravascular hemolysis associated with G6PD deficiency.

\section{Case Report}

A 7-year-old male child born to a nonconsanguineous parent presented with moderate grade fever, yellowish discoloration

received

July 28, 2014

accepted after revision

December 4, 2014

of eyes, and urine for the past 5 days before admission. There was no history of hematemesis, melena, or any other bleeding, swelling of body, convulsion, and drug ingestion just before present illness or any previous blood transfusion. His urine volume was satisfactory. On examination, the child was deeply icteric, severely anemic, and drowsy. Abdominal examination revealed soft hepatomegaly of $6.5 \mathrm{~cm}$ below right costal arch on right midclavicular line and enlarged spleen of approximately $3 \mathrm{~cm}$ below the left costal arch. There was no ascites. Except for drowsiness he had no neurological deficit; his plantar reflexes were flexor. Slit lamp examination of the eye did not reveal Keyser-Fleischer rings. On the day following admission, his urine color changed to dark brown or blackish.

Laboratory testing on admission showed a normocytic, normochromic anemia (hemoglobin $4.5 \mathrm{~g} / \mathrm{dL}$ ), reticulocyte count $14.1 \%$, and total leukocyte count $20,000 / \mathrm{mm}^{3}$ (neutrophils $80 \%$, lymphocytes $17 \%$, monocytes $2 \%$, and eosinophils $1 \%$ ). The platelet count was $350 \times 10^{9} /$ L. Prothrombin time was 15.9 seconds (control, 10.2 seconds), giving an international normalized ratio of 1.3 (normal, 1-1.2), and activated partial thromboplastin time was 23.5 seconds (normal, 22.635 seconds). The total serum bilirubin was $61.2 \mathrm{mg} / \mathrm{dL}$ (conjugated, $32.9 \mathrm{mg} / \mathrm{dL}$; unconjugated, $28.3 \mathrm{mg} / \mathrm{dL}$ ); serum total protein was $5.9 \mathrm{~g} / \mathrm{dL}$, and albumin and globulin were 3.6 and $2.3 \mathrm{~g} / \mathrm{dL}$, respectively, giving a albumin:globulin ratio of

Copyright $\odot 2015$ by Georg Thieme Verlag KG, Stuttgart · New York
DOI http://dx.doi.org/ 10.1055/s-0035-1554966. ISSN 1305-7707. 
1.57:1 (normal, 2:1). Liver enzymes were elevated as follows: aspartate aminotransferase 1,474 U/L (normal, 0-40 U/L), alanine aminotransferase $680 \mathrm{U} / \mathrm{L}$ (normal, 0-41 U/L) and alkaline phosphatase $354 \mathrm{U} / \mathrm{L}$ (normal, 100-250 U/L). Hepatitis A-specific IgM antibodies were detected in serum; serological tests for hepatitis $B, C$, and $E$ were negative. The results of Coombs direct and indirect antiglobulin tests were negative. Serum ceruloplasmin was $42.5 \mathrm{mg} / \mathrm{dL}$ (normal, $20-40 \mathrm{mg} / \mathrm{dL}$ ), and urinary copper excretion was $45 \mu \mathrm{g}$ during a 24-hour period (normal, 4-60 $\mu \mathrm{g}$ ). Challenge with two doses of penicillamine increased the 24-hour urine copper excretion to $150 \mu \mathrm{g}$. Urinalysis showed hemoglobinuria without erythrocytes. Tests for antinuclear antibody and antismooth muscle antibody were negative. Using the scoring system of the International Autoimmune Hepatitis Group the objective score was $<10$. A peripheral blood smear was negative for malaria, and a dual malaria antigen test was also negative. G6PD assay showed a level of enzymatic activity of $4.7 \mathrm{U} / \mathrm{g} \mathrm{Hb}$ (normal, 4.6-3.5 U/g).

The child was managed with intravenous fluid and mannitol to maintain his fluid-electrolyte balance. Cefotaxime was commenced empirically in case bacterial sepsis was the cause of initial presentation; this was continued to protect the child from developing sepsis, which is a common complication of FHF. The child was transfused 1 unit of concentrated RBCs. After 48 hours, he regained full consciousness, and after 3 to 4 days the urine discoloration improved. Two months later at outpatient follow-up, the patient had hepatomegaly of $2.5 \mathrm{~cm}$ below right costal arch, but no splenomegaly, anemia, or jaundice. Liver function test results had normalized; G6PD enzymatic activity was $1.30 \mathrm{U} / \mathrm{g} \mathrm{Hb}$.

\section{Discussion}

Hepatitis A virus infection is usually considered to be a mild disease, although severe, even fatal, cases can occur. ${ }^{6}$ In particular, G6PD deficient children are at risk of FHF, renal failure, hemolytic anemia, and severe hyperbilirubinemia. ${ }^{7}$ Acute hepatitis E infection with coexistent G6PD deficiency leading to acute hemoglobinuria without acute renal failure has also been reported. ${ }^{8}$ Likewise, hepatitis D superinfection in a chronic HBSAg carrier with G6PD deficiency has been associated with acute hemoglobinuria. ${ }^{9}$ Severe anemia without major blood loss is an unusual feature of hepatitis $A$ infection. In our case, the urine became blackish, rather than demonstrating the classic mustard oil color of bilirubinuria. The presence of severe anemia together with the urine appearance, severe jaundice, and splenomegaly made us suspect intravascular hemolysis. Acute hemoglobinuria is usually associated with only a few conditions, for example, mismatched blood transfusion, snake bite, G6PD deficiency, black water fever hemolytic uremic syndrome, autoimmune hemolytic anemia (especially an acute variety that occurs in children), Wilson disease. Black water fever was ruled out in this case. The G6PD enzyme level was low-normal during acute phase of our case, but it was found to be grossly reduced when retested during convalescence. This can occur because during an episode of acute hemolysis, peripheral blood con- tains an excess of young red cells that contain higher amounts of the G6PD enzyme. G6PD-deficient individuals usually appear clinically normal; however, acute hemoglobinuria can be precipitated by bacterial and viral infections, or by drugs, for example, primaquine, vitamin K, sulfonamides, nalidixic acid. In our case, acute hepatitis A infection was the precipitating factor. Earlier Hosnut et al $^{10}$ reported hemolysis in hepatitis A infection because of the autoimmune hemolytic anemia and G6PD deficiency, but in their case, administration of vitamin $\mathrm{K}$ was considered to have been a contributory factor.

Autoimmune hemolytic anemia was excluded in our case on the basis of negative autoimmune antibody and direct and indirect Coombs test results. Autoimmune hepatitis was ruled out by negative serological studies and by application of an objective scoring system. Despite acute hemoglobinuria, this patient did not develop acute renal failure, contrary to previous reports. ${ }^{7,8}$

G6PD catalyses the initial step in the hexose monophosphate shunt, oxidizing glucose-6-phosphate to 6-phosphogluconolactone, and reducing NADP to NADPH. The hexose monophosphate shunt pathway of glucose metabolism is the only red cell source of NADPH. NADPH acts as a cofactor for conversion of glutathione to reduced glutathione, which is essential to metabolize oxidant products within RBC. Thus, in the absence of reduced glutathione, RBC is vulnerable to hemolysis.

In conclusion, it is suggested that all patients with acute viral hepatitis A, marked hyperbilirubinemia and severe pallor should be assessed for acute intravascular hemolysis and G6PD deficiency. Universal vaccination against hepatitis A, or routine newborn screening for G6PD deficiency in Asian countries like India, would help avoid hepatitis A-associated acute intravascular hemolysis. Evidence in the form of large clinical- and cost-effectiveness studies is required to support a change in national policy.

\section{Conflict of Interest}

None.

Source of Funding

None.

Statement Regarding Informed Consent

The parents were informed about the suitability of the case for publication in a medical journal. They gave verbal consent in this regard.

\section{References}

1 Tandon BN, Gandhi BM, Joshi YK. Etiological spectrum of viral hepatitis and prevalence of markers of hepatitis $A$ and $B$ virus infection in north India. Bull World Health Organ 1984;62(1): $67-73$ 
2 Beutler E. G6PD deficiency. Blood 1994;84(11):3613-3636

3 Sarkar S, Prakash D, Marwaha RK, et al. Acute intravascular haemolysis in glucose-6-phosphate dehydrogenase deficiency. Ann Trop Paediatr 1993;13(4):391-394

4 Lyons DJ, Gilvarry JM, Fielding JF. Severe haemolysis associated with hepatitis A and normal glucose-6-phosphate dehydrogenase status. Gut 1990;31(7):838-839

5 Tibble JA, Ireland A, Duncan JR. Acute auto immune haemolytic anaemia secondary to hepatitis A infection. Clin Lab Haematol 1997;19(1):73-75

6 Cuthbert JA. Hepatitis A: old and new. Clin Microbiol Rev 2001; 14(1):38-58
7 Mishra D, Singh R, Sibal A. Liver transplantation for fulminant hepatitis A infection. Indian Pediatr 2002;39(2):189-192

8 Monga A, Makkar RP, Arora A, Mukhopadhyay S, Gupta AK. Case report: Acute hepatitis E infection with coexistent glucose-6phosphate dehydrogenase deficiency. Can J Infect Dis Med Microbiol 2003;14(4):230-231

9 Mukerji N. Hemolytic anemia in a patient with G6PD deficiency and acute viral hepatitis. Internet J Hematol 2002;1(1):1

10 Ozbay Hosnut F, Ozcay F, Selda Bayrakci U, Avci Z, Ozbek N. Etiology of hemolysis in two patients with hepatitis A infection: glucose-6phosphate dehydrogenase deficiency or autoimmune hemolytic anemia. Eur J Pediatr 2008;167(12):1435-1439 